\title{
PENGARUH KEPUASAN KERJA, PERSEPSI DUKUNGAN ORGANISASI DAN KEPEMIMPINAN SPIRITUAL TERHADAP ORGANIZATIONAL CITIZENSHIP BEHAVIOR PADA PT MNC SKY VISION TBK
}

\author{
${ }^{1}$ Quisty Arinnandya, ${ }^{2}$ La Diadhan Hukama \\ ${ }^{1}$ Universitas YARSI Jakarta
}

Quisty.arinnadya@gmail.com

\begin{abstract}
The purpose of this study were 1) to analyze the influence of job satisfaction on organizational citizenship behavior. 2) To analyze the influence of perceived organizational support on organizational citizenship behavior. 3) To analyze the the influence of spiritual leadership on organizational citizenship behavior. The population in this study were employees of PT MNC Sky Vision TBK, with the number of 40 people. Data analysis used are validity, reliability testing, regression, $t$ test and the coefficient of determination. The results of the study showed that: (1) job satisfaction has positive and significant effects on organizational citizenship behavior (2) perceived organizational support has positive and significant effects to organizational citizenship behavior (3) spiritual leadership has positive and significant effects on organizational citizenship behavior (4) simultaneously all variables are affecting organizational citizenship behavior positively and significantly.
\end{abstract}

Keywords: job satisfaction, perceived organizational support, spiritual leadership, organizational citizenship behavior

\begin{abstract}
ABSTRAK
Tujuan dari penelitian ini adalah 1) untuk menganalisis pengaruh kepuasan kerja terhadap organizational citizenship behavior. 2) Untuk menganalisis pengaruh persepsi dukungan organisasi terhadap organizational citizenship behavior. 3) Untuk menganalisis pengaruh kepemimpinan spiritual terhadap organizational citizenship behavior. Populasi dalam penelitian ini adalah karyawan PT MNC Sky Vision TBK, dengan jumlah 40 orang. Analisis data yang digunakan adalah validitas, uji reliabilitas, regresi, uji t dan koefisien determinasi. Hasil penelitian menunjukan bahwa: (1) kepuasan kerja memiliki pengaruh positif dan signifikan terhadap organizational citizenship behavior (2) persepsi dukungan organisasi memiliki pengaruh positif dan signifikan terhadap organizational citizenship behavior (3) kepemimpinan spiritual memiliki pengaruh positif dan signifikan terhadap organizational citizenship behavior (4) secara simultan seluruh variabel memiliki pengaruh yang positif dan signifikan terhadap organizational citizenship behavior.
\end{abstract}

Kata Kunci: kepuasan kerja, dukungan organisasi, kepemimpinan spiritual, perilaku organisasi

\section{PENDAHULUAN}

Sumber daya manusia adalah salah satu elemen penting organisasi dalam mencapai tujuannya. Dalam mencapai tujuannya berbagai tantangan yang dihadapi oleh organisasi seperti perubahan-perubahan yang terjadi baik di lingkungan eksternal dan internal organisasi. Perusahaan yang unggul adalah perusahaan mampu beradaptasi dengan perkembangan atau perubahan yang terjadi.

Agar mampu bersaing, perusahaan membutuhkan karyawan yang mampu memahami dan menerjemahkan dengan baik mengenai visi dan misi perusahaan agar produktivitas perusahaan dapat meningkat. Dengan demikian maka konstribusi karyawan untuk meningkatkan produktivitas perusahaan sangat dibutuhkan, namun disisi lain, perusahan harus memberikan hal-hal yang menjadi keinginan karyawan.

Berdasarkan penelitian yang dilakukan oleh Katz 1964 dalam (Smith dkk, 1983), diidentifikasikan tiga kategori perilaku karyawan yang diperlukan agar oganisasi berfungsi dengan baik, efektif, dan efisien yaitu: (a) Karyawan harus berada dalam sistem, melalui proses rekruitmen, rendahnya absensi, dan turn-over. (b) Karyawan melakukan peran yang diminta sesuai dengan 
deskripsi tugasnya dengan memenuhi standar kualitas maupun kuantitas yang ditetapkan. (c) Menunjukkan perilaku inovatif dan spontan diluar deskripsi peran yang ditetapkan untuk mencapai tujuan, antara lain mau bekerja sama dengan rekan kerja, melindungi sumber daya organisasi, memberikan saran yang konstruktif bagi peningkatan kinerja departemen atau organisasi secara umum, meningkatkan kemampuan pribadi melebihi yang disyaratkan oleh organisasi, dan menciptakan iklim yang baik bagi organisasi di lingkungan luar.

Berdasarkan kategorisasi yang dilakukan oleh Katz, dapat disimpulkan bahwa, kategori pertama dan kedua disebut sebagai the in role behavior sedangkan kategori yang ketiga sering disebut sebagai the extra role behavior, atau biasa disebut dengan organizational citizenship behavior.

Dengan demikian dapat disimpulkan bahwa sebuah organisasi tidak akan dapat efektif dan efisien apabila hanya mengandalkan pada perilaku-perilaku yang ada dalam deskripsi pekerjaan saja (in-role). Karyawan diharapkan mau berperilaku melebihi apa yang ada dalam deskripsi pekerjaannya yaitu perilaku extra-role.

Kepuasan kerja, dukungan yang diberikan perusaahan kepada karyawan atau persepsi dukungan organisasi, serta kepemimpinan spiritual dalam sebuah perusahaan akan menumbuhkan the extra role behavior atau perilaku kewarganegaraan organisasi bagi karyawan yang lebih dikenal dengan organizational citizenship behavior (OCB).

Dewasa ini tingkat persaingan dalam bisnistelevisi berlangganan semakin tinggi. Hal tersebut ditandai jumlah perusahaan yang menawarkan televisi berlangganan meningkat dari tahun ke tahun. Disisi lain, perusahaan tersebut tidak hanya menawarkan TV berbayar tapi sudah menawarkan layanan triple play yaitu layanan akses internet, TV berbayar, dan telephony.

Gencarnya perusahaan triple play dalam memasarkan layanannya secara tidak langsung berpengaruh kepada pemain TV berbayar yang mengandalkan satelit atau dikenal Direct To Home (DTH) khusunya MNC Sky Vision yang dikenal dengan merek dagang Indovision yang menguasai pangsa pasar sebesar $74,6 \%$ berkat total jumlah pelanggan 2,43 juta TV berbayar. (www.indotelko.com)

Ketatnya persaingan tersebut, akan memberikan tantangan tersendiri bagi perusahaan baik dari luar maupun dari dalam perusahaan. Salah satu tantangan yang dihadapi perusahaan adalah bagaimana mengelola pekerjaan yang akan dilakukan oleh karyawan, baik dari sisi deskripsi pekerjaan ataupun karakteristik pekerjaan. Dengan munculnya berbagai pengetahuan dan keterampilan yang dimiliki manusia, akan menambah variasi pekerjaan yang ada.

Terkadang karena banyaknya tugas yang kerjakan akan menimbulkan kesulitan dalam berperilaku extra, misalnya membantu rekan kerja lain yang sedang kesulitan atau menghadapi masalah dalam pekerjaannya.

Berdasarkan ulasan tersebut, maka penelitian ini akan menganalisis pengaruh kepuasan kerja, dukungan organisasi dan kepemimpinan sipritual terhadap organizational citizenship behavior PT MNC Sky Vision TBK.

\section{TINJAUAN PUSTAKA}

\section{Kepuasan Kerja}

Kepuasan kerja karyawan memiliki peranan yang penting dalam rangka menciptakan kinerja yang optimal bagi perusahaan. Karyawan yang memiliki kepuasan tinggi dalam pekerjaannya akan memiliki kinerja yang lebih baik dalam menjalankan tugasnya dibandingkan dengan mereka yang merasa tidak puas. Hal tersebut harus didukung dengan pengaturan dan pengelolaan manajemen sumber daya manusia secara profesional yang biasanya dimulai sejak tahap perekrutan karyawan, penyeleksian, pengklasifikasian, penempatan karyawan sesuai bidang, penataran dan pengembangan kariernya hingga pemberian kompensasi yang layak dan adil (Mangkunegara, 2011).

Menurut Luthans (2008), kepuasan kerja adalah keadaan emosional yang positif dari seseorang yang ditimbulkan dari penghargaan atas sesuatu pekerjaan yang telah dilakukannya.

Ciri perilaku pekerja yang puas menurut Suryana (2007), adalah mereka yang mempunyai motivasi yang tinggi untuk bekerja, mereka lebih senang dalam melakukan pekerjaannya, sedangkan ciri 
pekerja yang kurang puas adalah mereka yang malas berangkat kerja ke tempat bekerja, dan malas dalam melakukan pekerjaannya.

Sementara itu, untuk mengukur kepuasan kerja seorang karyawan menurut Rivai (2010) ada beberapa indikator yang digunakan antara lain adalah 1) isi pekerjaan, penampilan tugas pekerjaan yang aktual dan sebagai kontrol terhadap pekerjaan, 2) supervisi, 3) organisasi dan manajemen, 4) kesempatan untuk maju, 5) gaji dan keuntungan dalam bidang finansial lainnya, seperti adanya insentif, 6) rekan kerja dan 7) kondisi pekerjaan

\section{Persepsi Dukungan Organisasi}

Mangundjaya (2012) menyatakan bahwa untuk memenuhi kebutuhan sosio emosional dan menilai keuntungan dari peningkatan usaha dalam bekerja, karyawan membentuk persepsi umum mengenai sejauh mana organisasi menghargai kontribusinya dan peduli terhadap kesejahteraannya yang disebut sebagai persepsi dukungan organisasi. Kepedulian karyawan terhadap organisasi dan pencapaian tujuan organisasi tersebut dapat ditunjukkan dengan menampilkan sikap positif dan perilaku kerja yang sesuai dengan apa yang diharapkan oleh organisasi. Dukungan yang diberikan oleh organisasi akan menciptakan persepsi karyawan.

Perlakuan-perlakuan yang diterima oleh karyawan akan ditangkap sebagai stimulus dan diorganisir serta diinterpretasikan menjadi persepsi atas dukungan organisasi. Persepsi ini akan menumbuhkan tingkat kepercayaan tertentu dari karyawan atas penghargaan yang diberikan organisasi terhadap kontribusi mereka. Menurut Eisenberger (2008), persepsi dukungan organisasi sebagai keyakinan global karyawan mengenai sejauh mana organisasi peduli terhadap kesejahteraan mereka dan menghargai kontribusi mereka.

Robbins (2008) mengatakan bahwa persepsi dukungan organisasi adalah tingkat sampai mana karyawan yakin organisasi menghargai kontribusi mereka dan peduli dengan kesejahteraan mereka. Dukungan dari atasan juga sangat mempengaruhi persepsi karyawan untuk dapat meningkatkan kinerja mereka. Ketika karyawan merasa telah didukung oleh organisasi, maka akan muncul hukum timbal balik norm of reciprocity, dimana individu yang diperlakukan dengan baik oleh pihak lain akan merasa berkewajiban membalasnya dengan perlakuan yang baik pula (Gouldner, 1960). Dengan demikian, timbal balik ini dilakukan baik oleh organisasi maupun karyawan, dimana perlakuan baik yang diterima salah satu pihak, maka salah satu pihak mersa berkewajiban membalas perlakuan balik tersebut sehingga dapat menghasilkan keuntungan bagi kedua belah pihak.

\section{Kepemimpinan Spiritual}

Kepemimpinan spiritual merupakan kepemimpinan yang membawa dimensi keduniawian kepada dimensi spiritual (keilahian) dan lebih banyak mengandalkan kecerdasan spiritual dalam kegiatan kepemimpinan (Tabroni, 2005) dalam (Sulistyo, 2009)

Disamping itu, kepemimpinan spiritual merupakan kepemimpinan yang sangat menjaga nilai-nilai etis dan menjunjung tinggi nilai-nilai spiritual. Dimana kepemimpinan tersebut yang berbasis etika religius seperti: kejujuran hati, fairness, pengenalan diri sendiri, fokus pada amal shaleh, spiritualisme yang tidak dogmatis, bekerja lebih efisien, membangkitkan yang terbaik dalam diri sendiri dan orang lain, keterbukaan menerima perubahan, disiplin tetapi tetap fleksibel, santai dan cerdas, serta kerendahan hati (Sulistyo, 2009).

Menurut Fry (2003), kepemimpinan spiritual merupakan kumpulan nilai-nilai, sikap, dan perilaku yang diperlukan untuk memotivasi diri sendiri maupun orang lain secara intrinsik, sehingga masing-masing memiliki rasa pertahanan spiritual melalui kebermaknaan kerja dan keanggotaan. Ketika fungsi motivasi intrinsik ini dapat bekerja dengan baik, maka setiap pegawai akan terlibat dalam suatu organisasi yang pada akhirnya akan meningkatkan kinerja organisasi (Fry, 2003). Fry membangun teori kepemimpinan spiritual melalui kekuatan motivasi instrinsik yang bersumber dari nilainilai spiritual yang ada dalam diri manusia

Kepemimpinan spiritual bertujuan untuk memenuhi kebutuhan dasar psikologi karyawan seperti kebermaknaan kerja dan keanggotaan, menciptakan penglihatan dan konsistensi antara nilai-nilai lintas-organisasi yang diberdayakan individu dan kelompok yang akhirnya dapat meningkatkan 
keuntungan, pertumbuhan, dan kesejahteraan organisasi (Fry, 2003).

Saat ini banyak orang yang bekerja hanya untuk memenuhi kebutuhan ekonomi dan status, bukan karena mencintai pekerjaannya dan menemukan makna hidup melalui pekerjaannya (Widyarini, 2008). Spiritualitas di tempat kerja tidak dapat diharapkan berkembang sendiri tanpa adanya dukungan dari pimpinan. Dari sudut pandang spiritual, peran seorang pemimpin adalah untuk memobilisasi kekuatan karyawan yang potensial dan dapat memandunya untuk mencapai tujuan akhir mereka (Fry, 2003).

\section{Organizational Citizenship Behavior}

Organizational citizenship behavior didefinisikan sebagai "perilaku individu yang bersifat diskresioner, yang tidak secara langsung atau eksplisit termasuk dalam sistim imbalan, dan secara keseluruhan akan meningkatkan efektivitas fungsi organisasi (Organ, 1988) dalam Olowookere (2014). Menurut Purnamie (2014), Organizational Citizenship Behavior (OCB) adalah perilaku karyawan yang tidak nampak baik terhadap rekan kerja maupun terhadap perusahaan, di mana perilaku tersebut melebihi dari perilaku standar yang ditetapkan perusahaan dan memberikan manfaat bagi perusahaan.

Bogler dan Somech (2005) mengatakan bahwa OCB adalah perilaku sekehendak hati yang diarahkan oleh individu atau organisasi secara keseluruhan. Sedangkan, Smith dkk. (1983), menyatakan bahwa OCB sebagai bentuk kontribusi pekerja terhadap organisasi dan di luar dari deskripsi pekerjaan formal. Disamping itu, seorang karyawan tidak akan dihukum apabila ia memilih untuk tidak melakukan prilaku OCB tersebut. Sebagai contoh, adanya bantuan terhadap rekan kerja untuk meringankan beban kerja, mengurangi waktu istirahat, melaksanakan pekerjaan yang tidak diminta, dan berisnisiatif membantu orang lain dalam menyelesaikan tugas dan lain-lain.

Dengan demikian, organizational citizenship behavior dapat didefinisikan sebagai: a) perilaku yang bersifat sukarela dan tidak ada unsur pemaksaan dalam organisasi; b) Perilaku yang muncul tanpa perintah resmi; c) tidak berhubungan langsung dengan sistem konpensasi dalam perusahaan; dan d) seorang karyawan tidak akan dihukum apabila ia memilih untuk tidak melakukan prilaku OCB tersebut

Podsakoff dkk. 2000, menyimpulkan bahwa ada beberapa alasan mengapa perilaku $O C B$ dapat mempengaruhi efektivitas organisasi, yaitu: 1) Membantu rekan kerja menyelesaikan pekerjaan dan manajemen; 2) Membantu merampingkan penggunaan sumber daya organisasi untuk tujuan produktif, 3) Menurunkan tingkat kebutuhan sumber daya organisasi untuk tujuan produktif; 4) Efektif kebijakan untuk koordinasi kegiatan antara anggota tim dan latar belakang dari kelompok kerja; 5 . Meningkatkan kemampuan organisasi untuk mempertahankan sumber daya manusia untuk beradaptasi dengan efek bahwa pekerjaan organisasi adalah menarik; 6) Meningkatkan stabilitas kemampuan kerja organisasi; dan 7) Meningkatkan kemampuan organisasi untuk beradaptasi dengan perubahan dalam lingkungan pekerjaan.

Menurut Organ (1988) dalam Jahangir dkk (2004), ada lima dimensi organizational citizenship behavior, yaitu: 1). Altruisme, ini disebut dengan tindakan sukarela karyawan untuk membantu pekerja lain mengatasi masalah mereka; 2) Kegigihan, dimensi ini mengacu pada berbagai perilaku yang melebihi resolusi minimum sebagai ketepatan waktu, merampingkan bekerja dan menghemat sumber daya; 3) Sportif, kesediaan individu untuk menanggung penderitaan tanpa mengeluh dan merasa dirugikan; 4) Peradaban, mengacu pada tindakan jauh ke depan untuk membantu orang lain untuk menghindari membuat kesalahan atau memiliki masalah; dan 5) Civic Virtue, menunjukkan keterlibatan dan ikut bertanggung jawab dalam kegiatan-kegiatan organisasi dan peduli pada kelangsungan hidup organisasi

\section{METODE}

Jenis penelitian ini adalah penelitian deskriptif dengan metode kuantitatif. Penelitian jenis deskriptif dipilih karena penelitian yang akan dilakukan bertujuan untuk mendapatkan informasi mengenai bagaimana pengaruh kepuasan kerja, dukungan organisasi dan kepemimpinan sipritual terhadap organizational citizenship behavior PT MNC Sky Vision TBK. Populasi dalam penelitian ini adalah seluruh karyawan 
Divisi Corporate Secretary/Legal dan Divisi Compliance Audit di PT MNC Sky Vision Tbk yang berjumlah 50 orang. Dengan demikian, seluruh pegawai perusahaan tersebut dijadikan sampel. Sedangkan teknik pengambilan sampel yang digunakan adalah teknik sampling jenuh dimana semua anggota populasi dijadikan sampel Sugiyono (2012). Teknik pengumpulan data dalam penelitian ini melalui kuesioner. Angket dalam penelitian ini digunakan untuk memperoleh data tentang persepsi pegawai mengenai kepuasan kerja, persepsi dukungan organisasi, kepemimpinan spritual dan organizational citizenship behavior. Angket / kuesioner tersebut disebarkan kepada sampel yang telah ditetapkan yaitu seluruh pegawai Divisi Corporate Secretary/Legal dan Divisi Compliance Audit di PT MNC Sky Vision Tbk.

\section{HASIL DAN PEMBAHASAN Uji Kualitas Data}

Berdasarkan hasil pengujian validitas, terlihat bahwa seluruh variabel memiliki nilai koefisien yang lebih besar daripada 0,300. Hal tersebut menunjukkan bahwa seluruh item pernyataan dinyatakan valid sehingga tidak ada item pernyataan yang harus dibuang.

Sedangkan hasil dari uji reliabilitas dapat dilihat pada Tabel 1.

Tabel 1. Hasil Uji Reliabilitas

\begin{tabular}{|l|r|c|c|}
\hline \multicolumn{1}{|c|}{ Keterangan } & $\begin{array}{c}\text { Cronbach's } \\
\text { Alpha }\end{array}$ & $\mathbf{r}_{\text {-tabel }}$ & Ket. \\
\hline $\begin{array}{l}\text { Kepuasan } \\
\text { Kerja }\end{array}$ & 0,975 & 0,312 & Reliabel \\
\hline $\begin{array}{l}\text { Persepsi } \\
\text { Dukungan } \\
\text { Organisasi }\end{array}$ & 0,923 & 0,312 & Reliabel \\
\hline $\begin{array}{l}\text { Kepemimpinan } \\
\text { Spiritual }\end{array}$ & 0,949 & 0,312 & Reliabel \\
\hline $\begin{array}{l}\text { Organizational } \\
\text { Citizenship } \\
\text { Behavior }\end{array}$ & 0,931 & 0,312 & Reliabel \\
\hline
\end{tabular}

Sumber: data diolah, 2017

Berdasarkan hasil pengujian reliabilitas, dapat diketahui bahwa seluruh variabel memilikinilai cronbach's alpha yang lebih besar $r_{\text {-tabel }}$. Dengan demikian seluruh variabel baik variabel bebas maupun terikat dinyatakan reliabel.

\section{Analisis Regresi Linier Berganda}

Analisi regresi linear berganda digunakan untuk menentukan pengaruh yang ditimbulkan oleh indikator variabel bebas terhadap variabel terikat. Hasil dari regresi linier berganda antara variabel kepuasan kerja $\left(\mathrm{X}_{1}\right)$, persepsi dukungan organisasi $\left(\mathrm{X}_{2}\right)$, dan kepemimpinan spritual $\left(\mathrm{X}_{3}\right)$ terhadap variabel organizational citizenship behavior (Y), dapat dilihat pada Tabel 2 .

Tabel 2. Hasil Regresi Linear Berganda

\begin{tabular}{|l|c|c|c|c|c|}
\hline \multirow{4}{*}{ Model } & \multicolumn{2}{|c|}{$\begin{array}{c}\text { Unstandardized } \\
\text { Coefficients }\end{array}$} & $\begin{array}{c}\text { Standardized } \\
\text { Coefficients }\end{array}$ & \multirow{2}{*}{ S Sig. } \\
\cline { 2 - 5 } & $\mathbf{B}$ & $\begin{array}{c}\text { Std. } \\
\text { Error }\end{array}$ & Beta & & \\
\hline Constant) &, 338 &, 314 & & $1,074,290$ \\
\hline KK &, 234 &, 108 &, 332 & 2,169 &, 037 \\
\hline PDO &, 361 &, 130 &, 365 & $2,782,009$ \\
\hline KS &, 279 &, 115 &, 285 & 2,423 &, 021 \\
\hline
\end{tabular}

Sumber: Data diolah

Ket: $\mathrm{KK}=$ kepuasan kerja

$\mathrm{PDO}=$ persepsi dukungan organisasi

$\mathrm{KS}=$ kepemimpinan spiritual

Dari hasil uji regresi linear berganda tersebut dapat diketahui rumus persamaan sebagai berikut :

$$
Y=0,338+0,234 X_{1}+0,361 X_{2}+0,279 X_{3}
$$

Dari rumus persamaan di atas, dapat dijelaskan interpertasinya sebagai berikut:

1. Nilai konstanta bernilai positif, hal ini menunjukkan bahwa apabila variabel kepuasan kerja, persepsi dukungan organisasi dan kepemimpinan spiritual dianggap tidak ada atau sama dengan 0 , maka variabel organizational citizenship behavior akan memiliki nilai sebesar 0,338 .

2. Koefisien regresi variabel kepuasan kerja bernilai positifyaitu sebesar 0,397 , hal ini menunjukan bahwa variabel tersebut mempunyai pengaruh yang positif terhadap organizational citizenship behavior.

3. Koefisien regresi variabel persepsi dukungan organisasi bernilai positif yaitu sebesar 0,361. Hal ini menunjukkan bahwa variabel tersebut mempunyai pengaruh yang positif terhadap organizational citizenship behavior.

4. Koefisien regresi variabel kepemimpinan spiritual bernilai positif yaitu sebesar 0,279 . Hal ini menunjukan bahwa 
variabel tersebut mempunyai pengaruh yang positif terhadap organizational citizenship behavior.

\section{Hasil Uji Hipotesis}

Berdasarkan hasil Uji t seperti terlihat pada Tabel 2 menunjukkan bahwa hipotesis variabel kepuasan kerja memiliki pengaruh yang positif dansignifikan terhadap OCB. Hal ini ditunjukkan dengan nilai signifikansi sebesar 0,037 $(\alpha<0,05)$.

Hal yang sama ditunjukkan oleh variabel persepsi dukungan organisasi dan kepemimpinan spiritual organisasi yang memiliki pengaruh yang signifikan terhadap OCB dimana masing-masing variabel tersebut memiliki nilai signifikansi $0,009(\alpha<0.05)$ dan nilai signifikansi $0,021(\alpha<0.05)$.

\section{Tabel 3. Hasil Uji F (Uji Simultan} ANOVA $^{\mathrm{a}}$

\begin{tabular}{|l|l|l|l|l|l|}
\hline \multicolumn{1}{|c|}{ Model } & $\begin{array}{c}\text { Sum of } \\
\text { Squares }\end{array}$ & df & $\begin{array}{c}\text { Mean } \\
\text { Square }\end{array}$ & F & Sig. \\
\hline Regression & 6,397 & 3 & 2,132 & 6,19 &, $000^{\mathrm{b}}$ \\
\hline Residual & 2,930 & 36 &, 081 & & \\
\hline Total & 9,327 & 39 & & & \\
\hline
\end{tabular}

a. Predictors: (Constant, kepuasan kerja, persepsi dukungan organisasi kepemimpinan spritual

b. DependentVariable: organizational citizenship behaviour

Sumber: data diolah, 2017

Berdasarkan hasil uji $\mathrm{F}$ pada Tabel 3, diketahui bahwa $F_{\text {hitung }}>F_{\text {tabel }}$ dimana $F_{\text {hitung }}$ sebesar 26,196 > 2,87. Dengan menggunakan signifikansi F kurang dari 5\% $(0,000<0,05)$, maka dapat disimpulkan bahwa secara simultan variabel kepuasan kerja, persepsi dukungan organisasi dan kepemimpinan spritual terhadap variabel organizational citizenship behavior.

Tabel 4. Hasil Koefisien Determinasi

\begin{tabular}{|l|l|l|l|l|}
\hline $\begin{array}{c}\text { Mode } \\
\mathbf{l}\end{array}$ & $\mathbf{R}$ & $\begin{array}{c}\mathbf{R} \\
\text { Square }\end{array}$ & $\begin{array}{c}\text { Adjuste } \\
\mathbf{d} \mathbf{R} \\
\text { Square }\end{array}$ & $\begin{array}{c}\text { Std. } \\
\text { Error of } \\
\text { the } \\
\text { Estimate }\end{array}$ \\
\hline 1 &, $828^{\mathrm{a}}$ &, 686 &, 660 &, 28531 \\
\hline
\end{tabular}

Sumber: data diolah, 2017

Berdasarkan Tabel 4 hasil analisisakoefisien determinasi tersebut diatas, diketahui bahwa besarnya nilai koefisien determinasi $\mathrm{R}^{2}$ sebesar 0,660 atau sebesar
66\%. Hal tersebut menunjukkan bahwa variabel kepuasan kerja, persepsi dukungan organisasi dan kepemimpinan spritual terhadap variabel organizational citizenship behavior pegawai di PT MNC Sky Vision Tbk., sedangkan sisanya sebesar $44 \%$, dipengaruhi oleh faktor-faktor lain yang tidak dimasukkan di dalam penelitian ini.

\section{Pembahasan}

Berdasarkan hasil analisa mengenai pengaruh kepuasan kerja, persepsi dukungan organisasi dan kepemimpinan spritual terhadap variabel organizational citizenship behavior pegawai di PT MNC Sky Vision Tbk akan diuraikan sebagai berikut:

1. Variabel kepuasan kerjaberpengaruh secara signifikan terhadap organizational citizenship behavior pegawai di PT MNC Sky Vision Tbk. Pengaruh variabel tersebut ditunjukkan dengan nilai koefisien regresi yang positif yaitu 0,234 dan nilai signifikansi uji parsial yaitu sebesar 0,037 $(\alpha<0,05)$. Berdasarkan hasil analisa, hal tersebut dapat diduga antara lain adalah perusahaan memberikan kesempatan untuk maju kepada semua karyawan dengan memberikan pelatihan dan pengembangan karir yang jelas. Disamping itu, adanya dukungan dari sesama rekan kerja dan karwayan merasakan adanya interaksi yang menyenangkan antar sesama karyawan.

2. Variabel persepsi dukungan organisasi berpengaruh secara signifikan terhadap organizational citizenship behavior pegawai di PT MNC Sky Vision Tbk. Pengaruh variabel tersebut ditunjukkan dengan nilai koefisien regresi yang positif yaitu 0,361 dan nilai signifikansi uji parsial yaitu sebesar $0,009 \quad(\alpha<0.05)$. Berdasarkan hasil analisa, hal tersebut dapat diduga antara lain adalah perusahaan peduli dengan kesejahteraan karyawannya, contohnya seperti memberikan asuransi kesehatan dan perencanaan karir yang jelas. Disisi lain perusahaan memberikan bantuan ketika karyawan sedang mengalami masalah.

3. Variabel persepsi kepemimpinan spritual berpengaruh secara signifikan terhadap organizational citizenship behavior pegawai di PT MNC Sky Vision Tbk. Pengaruh variabel tersebut ditunjukkan 
dengan nilai koefisien regresi yang positif yaitu 0,279 dan nilai signifikansi uji parsial yaitu sebesar 0,021 $(\alpha<0.05)$. Berdasarkan hasil analisa, hal tersebut dapat diduga antara lain adalah sebagian besar karyawan selalu berusaha lebih baik dalam bekerja agar perusahaan sukses. Karyawan juga yakin dengan perusahaan sehingga bersedia melakukan apa saja demi mencapai suksesnya misi perusahaan.

\section{SIMPULAN}

Berdasarkan hasil analisa, dapat ditarik kesimpulan bahwa seluruh variabel independen seperti kepuasan kerja, persepsi dukungan organisasi dan kepemimpinan spritual berpengaruh terhadap organizational citizenship behavior pegawai di PT MNC Sky Vision Tbk. Hal tersebut ditunjukkan oleh seluruh nilai koefisien regresi bernilai positif dan hasil uji hipotesis baik secara parsial maupun simultan menunjukan nilai yang signifikan.

\section{DAFTAR PUSTAKA}

Agustina, Hartiwi. 2012. Pengaruh Persepsi Dukungan Organisasi (Perceived Organization Support) terhadap Kinerja Dosen Melalui Motivasi Kerja (Studi Pada Sekolah Tinggi Ilmu EkonomiSTIE Palangka Raya). Jurnal Sains Manajemen. Vol. 1. No. 1. 2012. Hal. 15-29.

Arikunto, Suharsimi. 2010. Prosedur Penelitian Suatu Pendekatan Praktek. Jakarta: Rineka Cipta.

Bogler, Ronit dan Anit Somech. (2005). "Organizational Citizenship Behavior in School. How Does it Relate to Participation in Decision Making?" Journal of Educational Administration. Vol 43 No. 5, 2005 pp 420-438

Chen, Chin-Yi and Chin-Fang Yang. 2012. The Impact of Spiritual Leadership on Organizational Citizenship Behavior (A Multi-Sample Analysis). Journal of Business Ethics. Vol. 105. No. 1. Hal. 107-114.

Cushway, Barry. 2007. Human Resource Management. Jakarta: PT Elex Media Komputindo.

Eisenberger, R, F. Stinglhamber, C. Vandenberghe, I.L.Sucharski \& L.
Rhoades. 2008. Perceived Supervisor Support: Contributions To Perceived Organizational Support And Employee Retention. Journal of Applied Psychology. Vol. 87. No. 3. Hal. 565573.

Eisenberger, R, Robert Huntington, S. Hutchison \& D. Sowa. 2007. Perceived Organizational Support. Journal of Applied Psychology. Vol. 71. Hal. 500507.

Fry, L. W. 2003. Toward a theory of spiritual leadership. The Leadership Quarterly, $14,693-727$

Ghozali, Imam. 2011. Analisis Multivariate Dengan Program SPSS. Cetakan Empat. Semarang: Badan Penerbit Universitas Diponegoro.

Gouldner, Alvin W. The Norm of Reciprocity: A Preliminary Statement. American Sociological Review, Vol. 25, No. 2 (Apr., 1960), pp. 161-178

Helmy, Irfan. 2016. Pengaruh Spiritual Leadership dan Emotional Intelligence terhadap Organizational Citizenship Behaviour dengan Workplace Spirituality sebagai Variabel Intervening. Jurnal Bisnis dan Manajemen. Vol. 4. No. 1. Hal. 72-80.

Intifada, Ratna dan Harlina Nurtjahjanti. 2013. Hubungan Antara Perceived Organizational Support dengan Organizational Citizenship Behavior pada Karyawan Hotel Pandanaran Semarang. Jurnal Empati. Vol. 2. No. 3.

Jahangir, Nadim. Moh. Muzahir Akbar, \& Mahmudul Haq. 2004. Organizational Citizenship Behavior : Its Nature and Antecendents. BRAC University Journal, Vol. 1. No. 2. pp. 75-85.

Kaya, Ahmed. 2015. The Relationship between Spiritual Leadership and Organizational Citizenship Behaviors: A Research on School Principals Behaviors. Educational Science: Theory \& Practice. Vol. 15. No. 3. Hal. 597-606.

Kreitner, Robert and Angelo Kinicki, 2009. Organizational Behavior-5th Edition. Irwin McGraw-Hill.

Kuncoro, Mudrajat. 2007. Metode Kuantitatif, Teori dan Aplikasi untuk Bisnis dan 
Ekonomi. Yogyakarta: UPP STIM YKPN.

Kusumajati, Dian Anggraini. 2014. Organizational Citizenship Behavior (OCB) Karyawan Pada Perusahaan. Jurnal Humaniora. Bina Nusantara University, Indonesia. Vol.5 No.1 April 2014: 62-70

Luthans, Fred. 2008. Perilaku organisasi. Edisi Sepuluh. Yogyakarta : Penerbit Andi.

Mangkunegara, A.A. Anwar Prabu. 2011. Manajemen Sumber Daya Manusia Perusahaan. Bandung: PT Remaja Rosda Karya.

Mangundjaya, Wustari L.H. 2011. Hubungan Antara Perilaku Kewarganegaraan Organisasi, Psychological Capital, dan Workplace Well-Being terhadap Kesiapan Untuk Berubah. Laporan Penelitian Fakultas Psikologi Universitas Indonesia (Publikasi terbatas).

Mangundjaya, Wustari L.H. 2012. Persepsi Dukungan Organisasi Versus Kepuasan Kerja dan Perannya terhadap Perilaku Kewarganegaraan Organisasi. Jurnal Psikologi. Vol. 11. No. 2. 175-182

Manullang, Belferik, Sri Milfayetty, dan M.S. Kons. 2013. Human Resources Management Based On The Teacher's Empowering. 2012 International Conference on Information Technology and Management Science.

Olowookere, E.I., (2014). Organizational Citizenship Behaviors (OCB): a key to Industrial Development in Nigeria. In D.O. Imhonopi and U.M. Urim (Eds.), Trajectory to Industrial Development in Nigeria, Cardinal Prints, Ibadan, 367378 (12 pages).

Organ, D.W., Podsakoff, P.M., \& Mac Kenzie, S.B. 2007. Organizational citizenship behavior: Its Nature, Antecedents, and Consequences. United Kingdom: Sage Publications.

Podsakoff, P. M., et al. 2000. Organizational Citizenship Behavior: A Critical Review of The Theoretical and Empirical Literature and Suggestions for Future Research. Journal of Management, Vol. 26, No. 3. 513-563

Pratiwi, Suryani Dewi. 2013. Pengaruh Motivasi Kerja, Kepuasan Kerja,
Kepemimpinan Kepala Sekolah Menurut Persepsi Guru, Dan Iklim Sekolah Terhadap Kinerja Guru Ekonomi SMP Negeri Di Kabupaten Wonogiri. Jurnal Pendidikan Insan Mandiri. Vol. 2. No. 1. Hal. 89-100.

Purnamie, Titisari. 2014. Perananan Organizational Citizenship Behavior Dalam Meningkatkan Kinerja Karyawan. Jakarta: Mitrawacanamedia.

Putra, Danang Siaga. 2013. Hubungan antara Perceived Organizational Support dengan Organizational Citizenship Behavior pada Karyawan PT Enseval Putera Megatrading Divisi Transportasi Cabang Sidoarjo. Jurnal Psikologi Industri dan Organisasi. Vol. 2. No. 1.

Reave, L. 2005. Spiritual Values and Practices Related to Leadership Effectiveness. The Leadership Quarterly, 16(5), 655687.

Rhoades, L. and Eisenberger, R. 2009. Perceived Organizational Support: A Review Of The Literature. Journal of Applied Psychology, Vol. 87. Hal. 698714.

Rivai, Veithzal. 2010. Manajemen Sumber Daya Manusia Untuk Perusahaan: Dari Teori Ke Praktik. Jakarta: PT Raja Grafindo Persada.

Robbins, S.P. and Judge, T. 2008. Perilaku Organisasi. Jakarta: Salemba Empat.

Sambung, Roby. 2011. Pengaruh Kepuasan Kerja terhadap OCB-I dan OCB-O Dengan Dukungan Organisasi Sebagai Variabel Moderating (Studi pada Universitas Palangka Raya). Analisis Manajemen. Vol. 5. No. 2. Hal. 77-87

Shanock, L. and Eisenberger, R. 2011. When Supervisors Feel Supported: Relationships with Subordinates Perceived Supervisor Support, Perceived Organizational Support, and Performance. The Journal of Applied Psychology. Vol. 91. Hal. 689-695.

Soegandhi, VM. Eddy M. Sutanto dan Roy Setiawan. 2013. Pengaruh Kepuasan Kerja dan Loyalitas Kerja terhadap Organizational Citizenship Behavior Pada Karyawan PT. Surya Timur Sakti Jatim. Jurnal AGORA Vol. 1, No. 1.

Somantri, Ating dan Sambas Ali M. 2006. Aplikasi Statistika Dalam Penelitian. Bandung: Penerbit Pustaka Setia. 
Spector, P.E. 2012. Industrial and Organizational Psychology. United States of America: John Wiley \& Sons, INC.

Sugiyono. 2012. Metode Penelitian Kuantitatif Kualitatif dan $R \& D$. Bandung: Alfabeta.

Sulistyo, Heru. 2009. Analisis Kepemimpinan Spiritual dan Komunikasi Organisasional Terhadap Kinerja Karyawan. Jurnal Ekobis. Jurnal Ekobis Fakultas Ekonomi, Universitas Islam Sultan Agung Vol. 10 No.2 2009. Hal. 311-321

Sunyoto, D. 2012. Manajemen Sumber Daya Manusia. Yogyakarta : CAPS.

Supranto, J. 2008. Ekonometri, Buku Kesatu. Jakarta: Ghalia Indonesia.

Suryana, Sumantri. 2007. Perilaku Organisasi. Bandung: Universitas Padjajaran.

Sutrisno, Edy. 2011. Manajemen Sumber Daya Manusia. Jakarta: Prenada Media Group.

Umar, Husein. 2010. Desain Penelitian MSDM dan Perilaku Karyawan. Jakarta: PT Raja Grafindo Persada.

Widyarini, N. (2008). Spiritualitas masuk dunia kerja. Diunduh dari: https://nasional.kompas.com/read/2008/ 01/10/20074767/spiritualitas.masuk.du nia.kerja

Yuniar, I Gusti A.Y., Harlina Nurtjahjanti, dan Diana Rusmawati. 2011. Hubungan Antara Kepuasan Kerja dan Resiliensi dengan Organizational Citizenship Behavior (OCB) pada Karyawan Kantor Pusat PT BPD Bali. Jurnal Psikologi Undip. Vol. 9. No. 1. 